\title{
PENSANDO METAMORFOSES E MODOS DE TRABALHAR
}

\author{
Pensando metamorfosis y modos de trabajar \\ Thinking metamorphosis and ways to work
}

Helga Correa ${ }^{1}$

\begin{abstract}
Resumo
Nesse ensaio, registro reflexões sobre minha trajetória como pesquisadora em artes visuais, sobretudo aquelas correspondentes à década que vivemos, a dos anos 2010. São apresentados alguns resultados materiais das pesquisas que realizei, bem como as reflexões que motivaram e dão sentido a essas investigações que têm a natureza e suas relações com a sustentabilidade como preocupação e interesse.
\end{abstract}

Palavras-chave: Arte; Natureza; Poética; Resíduos

\section{Resumen}

En este ensayo presento reflexiones sobre mi trayectoria como investigadora en artes visuales, sobre todo las correspondientes a la década que vivimos. También presento algunos resultados materiales de las investigaciones que he realizado, o sea, las obras artísticas que he hecho, así como las reflexiones que motivaron y dan sentido a esas investigaciones. Todo el trabajo tiene como fondo mi preocupación e interés sobre el arte, la naturaleza y sus relaciones con la sostenibilidad.

Palabras-clave: Arte; Naturaleza; Poética; Residuo

\begin{abstract}
In this essay I record reflections on my trajectory as a researcher of visual arts, especially those corresponding to the decade we are living in. I'll present some results of the researches I have done, will shown some artwork produced in this period, as well as the reflections that motivated and give meaning to these investigations, that combine my concern and interest in the area of nature and their complex relations with problem of sustainability.
\end{abstract}

Keywords: Art; Nature; Poetic; Waste 


\title{
Trajetória como docente e pesquisadora
}

Nasci em Santa Maria, Rio Grande do Sul. Fiz graduação em Artes Gráficas na Universidade Federal de Santa Maria (UFSM), formando-me em 1998. Após um período em que trabalhei na iniciativa privada, na área de comunicação visual, no Rio de Janeiro, voltei a Santa Maria, onde defendi, em 2000, uma dissertação de mestrado, na área do Ensino em Artes. Em 2000, fiz concurso público para docente da UFSM, na área de gravura do Departamento de Artes Visuais (DAV). Fui nomeada e desde então sou responsável pelo Atelier de Gravura do DAV (atualmente Laboratório Arte Impressa). Em 2006, tendo recebido bolsa integral da CAPES, iniciei um projeto de doutoramento pleno no exterior. Em 2011 defendi minha tese de doutorado, na área da gravura no programa Artes y Educación, do Departamento de Dibujo da Faculdade de Bellas Artes na Universidade de Barcelona. Desde 2012 coordeno o Grupo de Pesquisa Arte Impressa do CNPq e atuo no Programa de Pós-Graduação em Artes Visuais da UFSM, PPGART.

\section{Metamorfoses}

Quando comecei a escrever sobre minha própria pesquisa, imediatamente reportei-me a um texto de Rosa Olivares, crítica objetiva, mordaz, que sempre me faz pensar em questões que por vezes ficam ocultas, dissimuladas nos meandros da produção acadêmica. Nesse texto, ela fala da necessária humildade ante nossa incapacidade de explicitação do que nosso próprio trabalho discorre ou tenciona fazê-lo, e da (im)possibilidade de alcance imediato do público. Obviamente que este é um tema que vem sendo explorado há anos, por vários autores, mas a autora é especialmente provocativa quando diz:

\begin{abstract}
Mantener la distancia adecuada es un consejo excelente para los artistas, que hacen sus obras pensando (más bien sin pensarlo) que cualquier espectador va a entender perfectamente, y nada más ver su obra, qué es lo que nos está contando, a qué hecho de la historia local de su país se refiere; que todos vamos a saber que esos dibujos están hablándonos de su infancia, del deseo inexplicable. No, querido artista, el espectador ve unos dibujos, un tapiz reconstruido, una escultura multiforme, unas fotos inconexas... difícilmente podemos adivinar qué te pasó en tu infancia, qué situaciones vivieron los pioneros de tu civilización; nosotros, los que miramos, sólo vemos lo que has hecho, pero no compartimos contigo nada más que unos momentos en una exposición, y tú no puedes estar siempre al lado de tu obra explicándonoslo todo, algo, por lo demás, poco atractivo y agotador. Guarda la distancia adecuada con tu obra, enfría la pasión, piensa en todo lo que no conoces. (OLIVARES, 2018)
\end{abstract}

Lembrei-me dessa passagem quando comecei a preparar esse ensaio. Optei por registrar, como em um catálogo imaginário de uma exposição retrospectiva, os temas que vêm me interessando e a forma como tenho explorado as questões relativas à arte e natureza.

Há tempos, os temas sobre arte e natureza me interessam. Na verdade, quase sempre usei de elementos simbólicos da natureza para estabelecer uma espécie de alegoria com o que se passava na minha vida interior. Naturalmente, ao associarmos a autobiografia, sempre há um cruzamento entre o factual e a ficção, um desafio entre registro e lembrança, entre criação e reelaboração, imaginação e memória. E isso foi bastante vívido durante vários trabalhos que realizei. Entretanto, o foco deste texto não é a análise biográfica, mas expor a relação constituída entre arte e natureza nos meus trabalhos, e o modo operativo que se apresentam neles.

\section{Arquivo Morto}

Esse trabalho faz parte de uma série onde centrei meu interesse nas folhas de árvores e arbustos. Nesse processo dei continuidade às minhas coleções de espécies naturais, iniciadas ainda nos anos 2000. Eu costumava coletar folhas em distintos habitats, por vezes em viagens, em lugares onde morei, por onde passei, por vezes pela mera beleza ou singularidade do material. Analisei suas estruturas, estabeleci várias correlações; permiti-me fazer associações sobre suas possíveis representações identitárias, indivíduos pertencentes a um universo, um complexo organismo: a árvore!

Ao longo deste período de trabalhos com as folhas, várias peças se alternaram: ora remetendo à importância e beleza destes indivíduos, ora ressaltando justamente a perda desta beleza e da vida, a doença, a extinção de espécies vegetais, a degradação natural delas.

O trabalho intitulado Arquivo Morto mostra um período de perplexidade ante a doença humana com consequências ambientais, são registros de uma flora e de uma artista em desalento, consternadas, abatidas, mas compelidas a reagir.

O trabalho consiste em uma série de envelopes de papel Kraft, etiquetados e numerados, que contêm radiografias, antigos prontuários médicos e folhas de várias espécies vegetais coladas sobre papel. Cada folha foi interferida de uma forma diferente, ora permitindo regiões majoritariamente transparentes, ora tornando o conjunto quase que completamente 
opaco à passagem da luz. As folhas ou fragmentos delas são contrastados com a fria imagem das radiografias, utilizadas originalmente para o diagnóstico de doenças ou investigação sobre o sistema respiratório. Os prontuários médicos estão associados à cada uma das imagens das radiografias e fazem referência direta a cada caso individualmente. O conjunto de envelopes é separado fisicamente em subgrupos por pranchas de MDF, como as que são rotineiramente utilizadas em arquivos de hospitais.

Figura 1- Arquivo Morto [Correa, Helga. Arquivo Morto, 2015, colagem / cera / radiografia / apontamentos pessoais, $21 \times 30 \mathrm{~cm}$, coleção da artista]

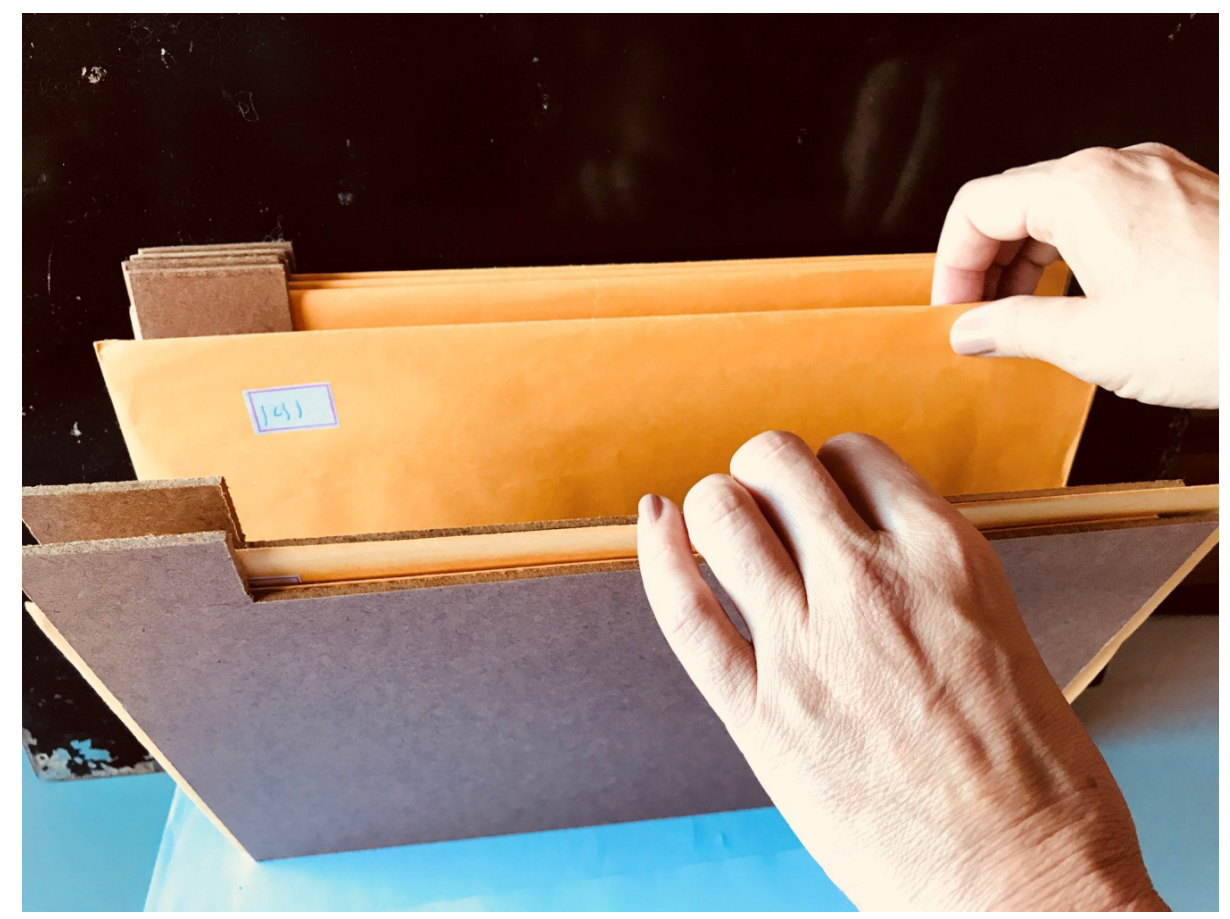

Figura 2 - Arquivo Morto [Correa, Helga. Arquivo Morto, 2015, colagem / cera / radiografia / apontamentos pessoais, $21 \times 30 \mathrm{~cm}$, coleção da artista]

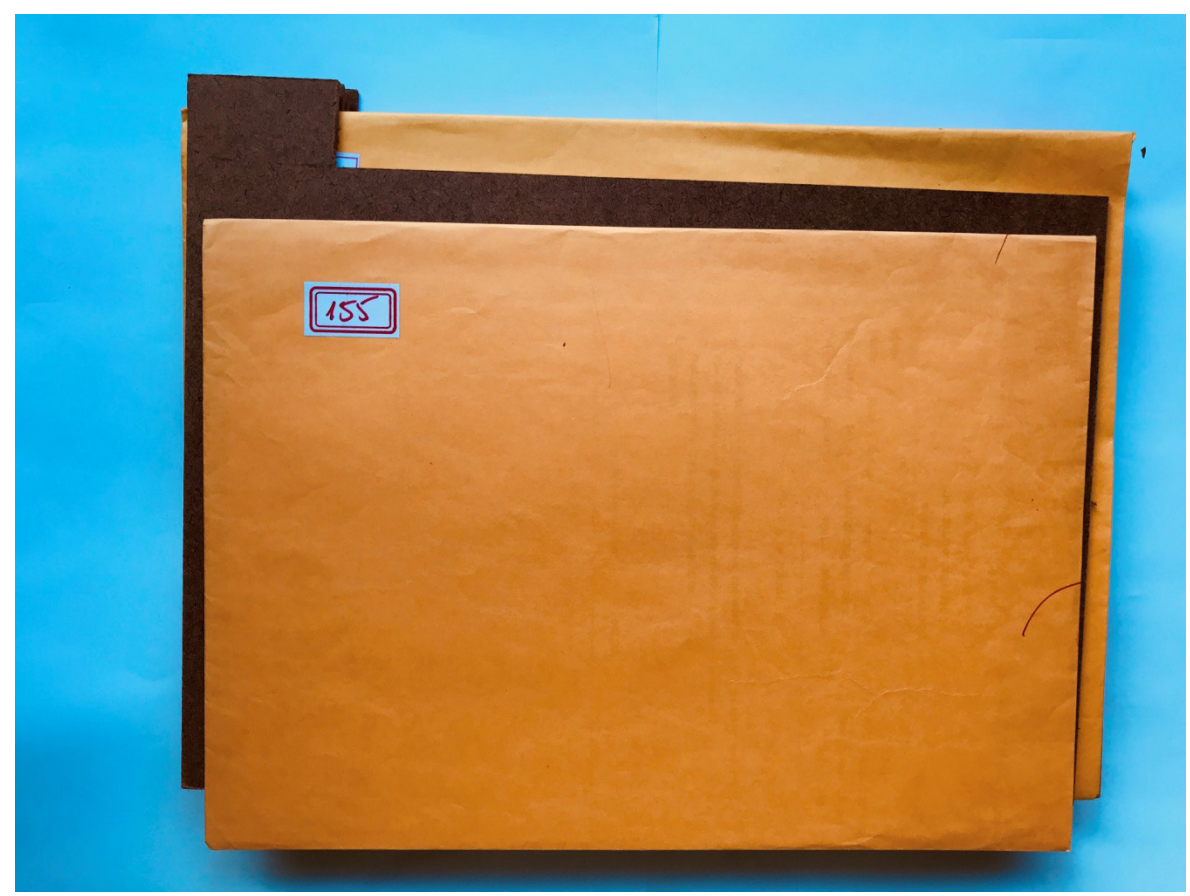


Figura 3 - Arquivo Morto [Correa, Helga. Arquivo Morto, 2015, colagem / cera / radiografia / apontamentos pessoais, $21 \times 30 \mathrm{~cm}$, coleção da artista]

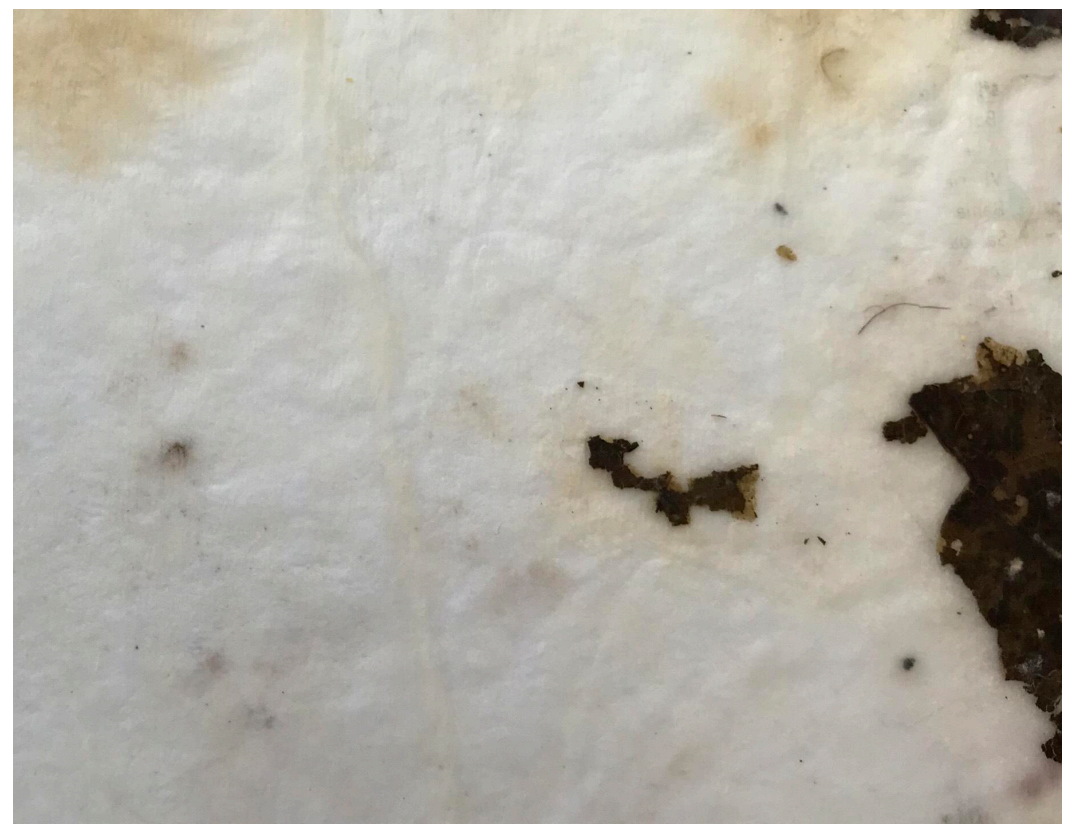

\section{Memória tangível da imortalidade}

No livro de artista, intitulado Memória tangível da imortalidade, de 2015, eu discutia a necessidade de preservação tanto daquilo que é ilustrado no livro (a arte têxtil popular), quanto daquilo que é orgânico, vivo (as folhas das árvores). O livro original que foi interferido era "Ornamente Der Volkskunst", publicado em 1949, pela editora alemã Ernest Wasmuth. Tratava-se de uma espécie de catálogo de clichês e motivos de arte têxtil, bordados, tapetes e tecidos de vários países europeus. Todas as pranchas originais faziam parte de coleções de museus e foram reunidas por um especialista em folclore europeu. Aleatoriamente, passei a incluir, entre as páginas do livro, pranchas de papel japonês, nas quais acrescentei e colei fragmentos de folhas de árvores, frutos secos, flores, sementes e ramos. As cores e formas das imagens originais do livro contrastam com os tons de cinza e verde das minhas coleções de resíduos vegetais.

Figura 4 - Memória tangível da imortalidade [Correa, Helga. Memória tangível da imortalidade, 2015, colagem, encadernação $32 \times 26 \mathrm{~cm}$, coleção da artista]

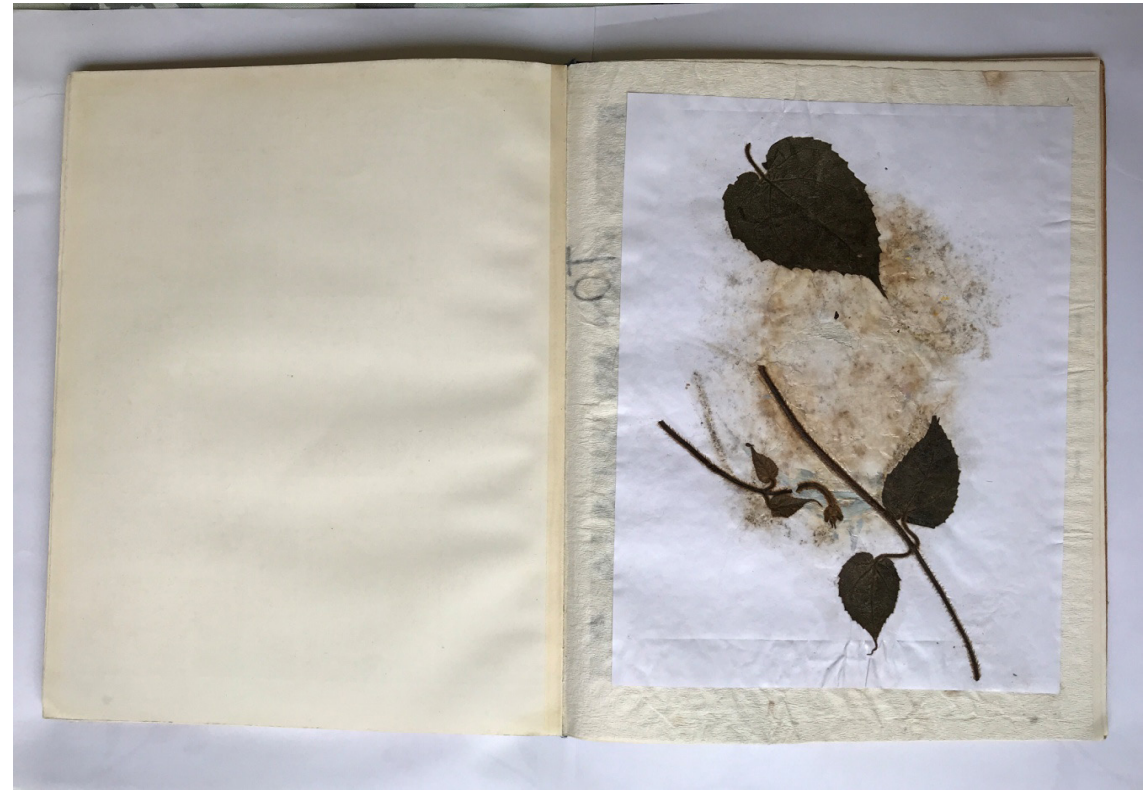


Figura 5 - Memória tangível da imortalidade [Correa, Helga. Memória tangível da imortalidade, 2015, colagem, encadernação $32 \times 26 \mathrm{~cm}$, coleção da artista]

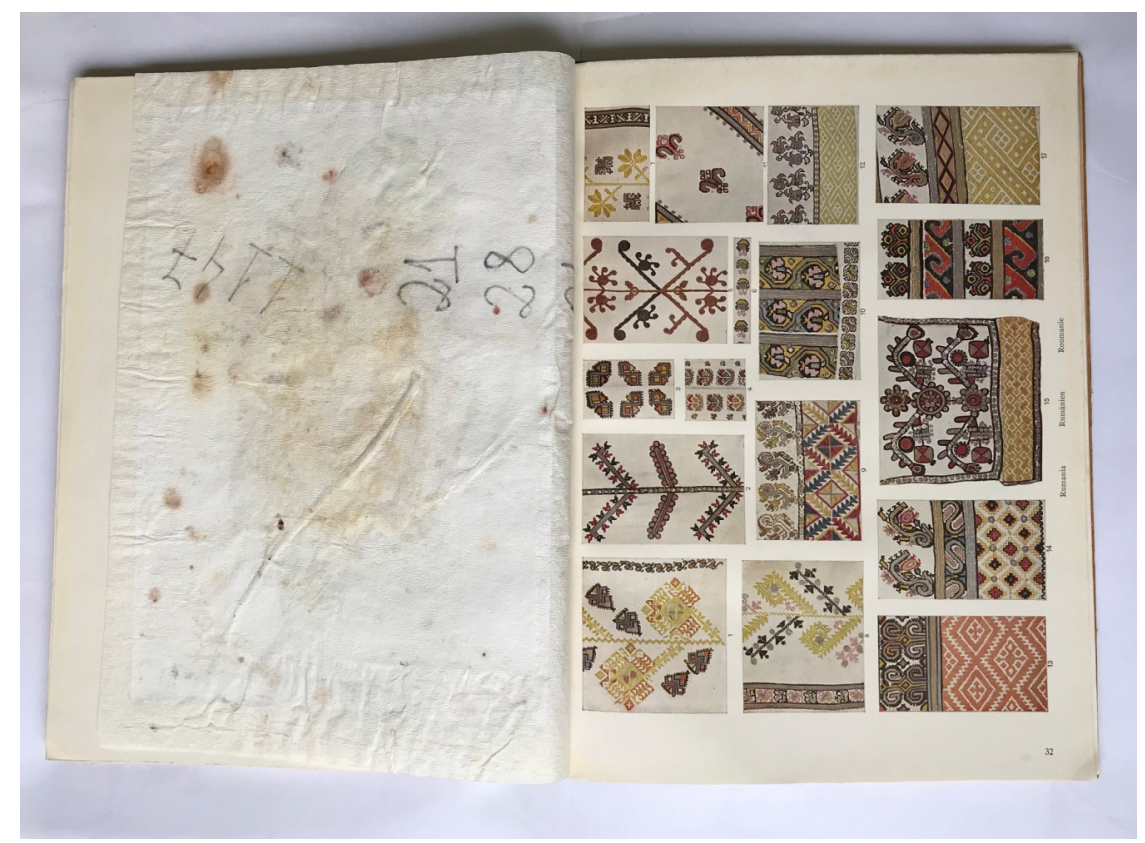

Existe beleza tanto na singularidade quanto na resiliência de ambos. As pessoas que preservam a natureza e aquelas que tecem ou bordam os fios fazem parte de um mesmo mundo e o veem de uma forma similar, onde é o tempo que permite a transformação de frutos em árvores e de fios em tecidos.

\section{Caixas de Mariana}

A tragédia ocorrida com o rompimento da barragem (Fundão) da mineradora Samarco em Mariana fez com que eu passasse a ser ainda mais pessimista em relação ao ser humano e sua relação com a natureza, o que me levou a mostrar nos trabalhos um mundo de resíduos e pequenas mortes. Comecei a incorporar explicitamente algo que emulasse as catástrofes ambientais provocadas pelo homem, em outros, dei ênfase na vida/morte dos pequenos animais que me cercam cotidianamente.

Desde então, vestígios da biodiversidade que me rodeia, materiais orgânicos, como pequenos peixes, insetos e plantas, foram unidos a resíduos inorgânicos como betumem, fragmentos de rochas, percloreto de ferro e tecidos (materiais com os quais trabalho nas aulas de introdução à gravura).

Estes materiais emulam os desastres ambientais causados pelo homem, expõem a morte de indivíduos que fazem parte da mesma cadeia natural que nós. Nestes trabalhos, os objetos foram transformados com um propósito racional, o que altera o processo de degradação natural, mas com o fim de salvar e preservar algo da beleza destas existências, dignificando sua capacidade de transformação e resiliência.

O trabalho é constituído por um conjunto de pelo menos 15 caixas, todas com a mesma dimensão. Na parte externa das caixas não há nenhuma indicação sobre o conteúdo de seu interior. As caixas foram forradas com folhas secas coletadas em uma residência artística. Na parte interior de cada uma das caixas sempre há suportes em tons terrosos sobre os quais apliquei betumem, cola e um pouco da tinta utilizada nos processos de gravura. Sobre as pranchas de lona, colei diversos materiais, tanto originalmente orgânicos como inorgânicos: penas de aves, carapaças de insetos, pequenos peixes, rochas, ramos, folhas e frutos de árvores, fotografias, fios cabelo e tecido. Algumas das pranchas de lona foram impressas utilizando-se da técnica de monotipia, simulando o registro da passagem de pequenos animas e aves sobre ela. O conjunto interior das caixas é explicitamente sujo, bruto, rude. O tempo parece nelas congelado. A morte das coisas e o destino dos objetos que se perderam na tragédia formam uma coisa só, que pouco guarda lembrança de sua natureza original. O derramamento as transformou em algo que ao mesmo tempo é bizarro e belo. O espectador das obras, quando em exposição, é incentivado a abrir as caixas, como quem procura por um objeto perdido, uma memória, um registro secreto das razões daquela tragédia. 
Figura 6 - Caixas de Mariana [Correa, Helga. Caixas de Mariana, Ano 2016, colagem/materiais orgânicos e inorgânicos, $34 \times 12 \mathrm{~cm}$, coleção da artista]

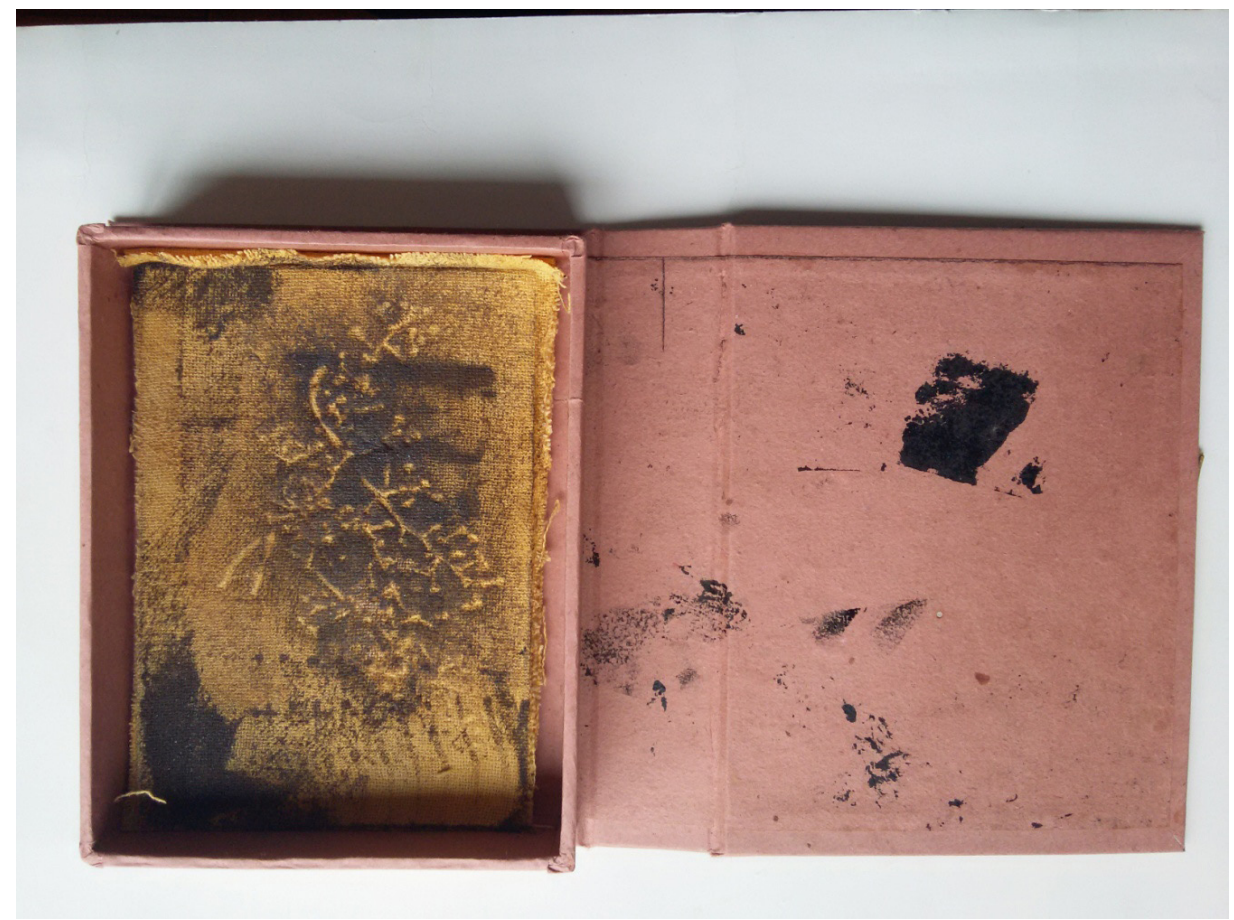

Figura 7- Caixas de Mariana [Correa, Helga. Caixas de Mariana, Ano 2016, colagem/materiais orgânicos e inorgânicos, $34 \times 12 \mathrm{~cm}$, coleção da artista]

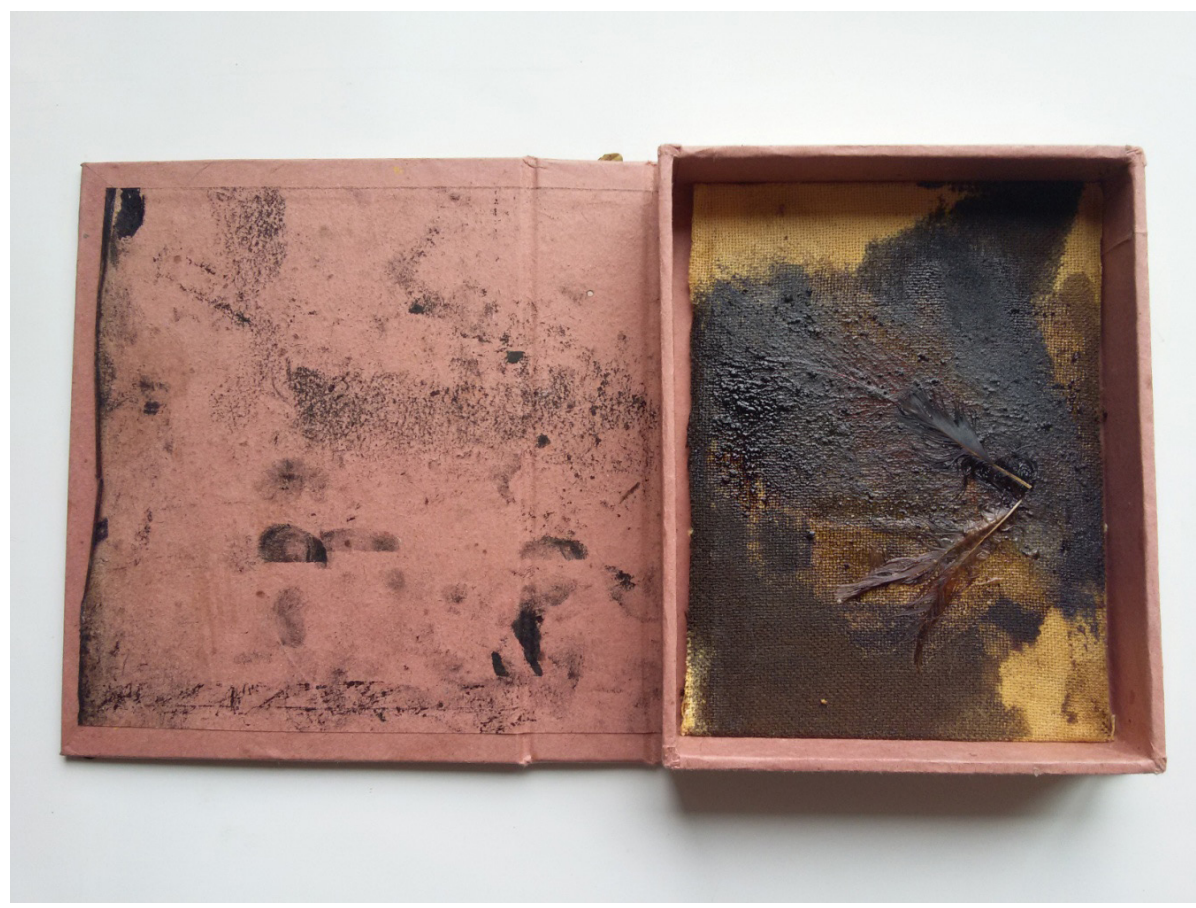




\section{Novas mutações}

Após um período de estudos e reflexões, venho trabalhando no que seria uma espécie de reorganização criativa da realidade que me preocupa, ou seja, a lenta e progressiva degradação da natureza e da vida. Dados divulgados nas últimas décadas por organizações como ONU, UNESCO e Greenpeace, indicam que tanto a curto quanto a longo prazo, as sazonais crises hídricas, a intensidade das mudanças climáticas, bem como a violência dos fenômenos atmosféricos, serão irreversíveis. Em função disso, minha estratégia, como cidadã preocupada com questões ambientais, tem sido sensibilizar aqueles que de alguma forma interagem comigo, utilizando-me de artifícios que apelam para a apreciação fortemente estética dos trabalhos, seja em sua negação, em sua total ausência, ou seja por sua predominância. Enfim, discuto e proponho reflexões sobre a realidade do entendimento do problema, por meio da força e transcendência da arte.

Outros artistas têm explorado o tema com diferentes abordagens, pontos de vista e modos operacionais, de forma a denunciar, provocar, colaborar, implicar algo novo à causa da interdependência ecológica. O documentário Rio de Lama, de Tadeu Jungle, tem sido uma importante referência sobre o acidente em Mariana. Neste processo, também senti enorme empatia pela obra de Miguel Angel Blanco, especialmente na sintaxe de Biblioteca del Bosque, que indica similitude com minha própria rotina de trabalho, já que percebo constante nesses trabalhos o mesmo modo de operar: coletar, secar, prensar, rasgar, colar. Constituir volumes, objetos e livros. Pequenas coleções pessoais da natureza.

Esse modo de operacionalizar os trabalhos surgiu de uma necessidade interna de manipulação e registro da realidade, é como se ao colar eu reciclasse sentimentos, pensamentos. É como se ao me apropriar destes elementos eu os reelaborasse, como se ao instaurar algo da reflexão estética, eu os tornasse mais significativos, desse maior visibilidade às suas vidas. Minhas coleções e obras, sejam elas de folhas, peixes, aracnídeos, miriápodes e coleópteros, podem garantir, ao menos, que houve a existência de dadas espécies em determinados períodos e lugares. Foi o caso da série "O Verão dos Besouros amarelos".

Figura 8 - Verão dos Besouros Amarelos [Correa, Helga. Verão dos Besouros Amarelos, 2018, colagem / verniz / matéria orgânica, $10 \times 14 \mathrm{~cm}$, coleção da artista]

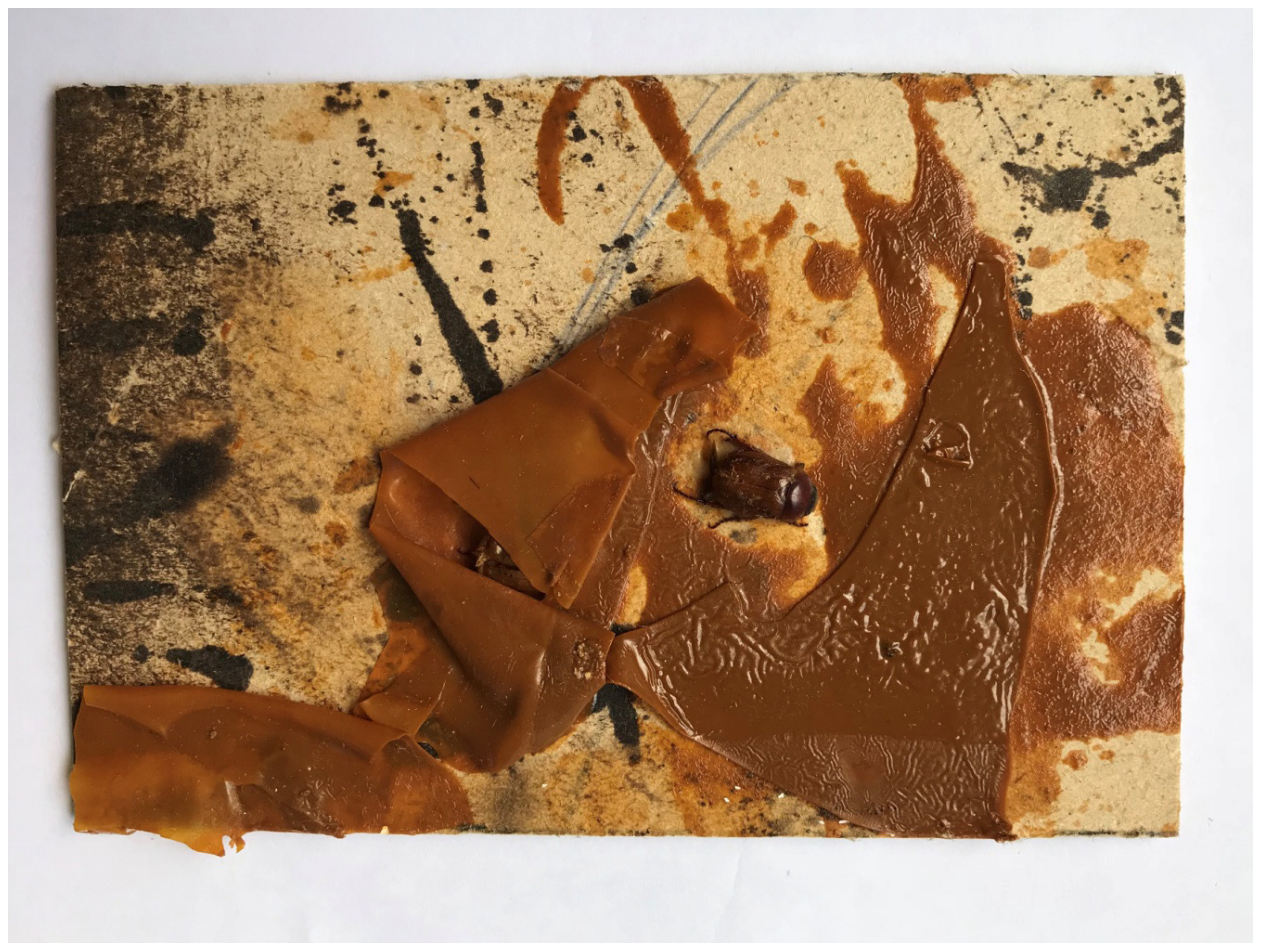

Durante o verão de 2018, passei as férias em um chalé na região serrana próxima a Santa Maria. Passei boa parte do verão pintando as janelas e as portas do chalé que era pré-fabricado, ou seja, tinha a madeira ainda em estado virgem. Fui orientada a passar uma espécie de selador, um verniz, para proteger a madeira, e consequentemente a casa, da ação da chuva e do sol. Comecei a pintura. As diferentes madeiras pintadas ficaram de um amarelo acastanhado lindo, com veios e manchas em diferentes tonalidades. Eu sempre trabalhava com pequenos potes para aplicar o verniz. Durante a noite havia muitos besouros amarelos que invadiam a área em busca da luz e eventualmente caíam dentro desses potes, que continham ainda um pouco de verniz no fundo. Muitas vezes, devolvi esses besouros de volta para a natureza, e era muito curioso observar como eram resistentes tanto à tinta quanto ao solvente que eu utilizava para limpar os pincéis. Mas muitos não conseguiram sobreviver e morreram enredados naqueles fluidos. 
Figura 9 - Verão dos Besouros Amarelos [Correa, Helga. Verão dos Besouros Amarelos, 2018, colagem / verniz / matéria orgânica, $10 \times 14 \mathrm{~cm}$, coleção da artista]

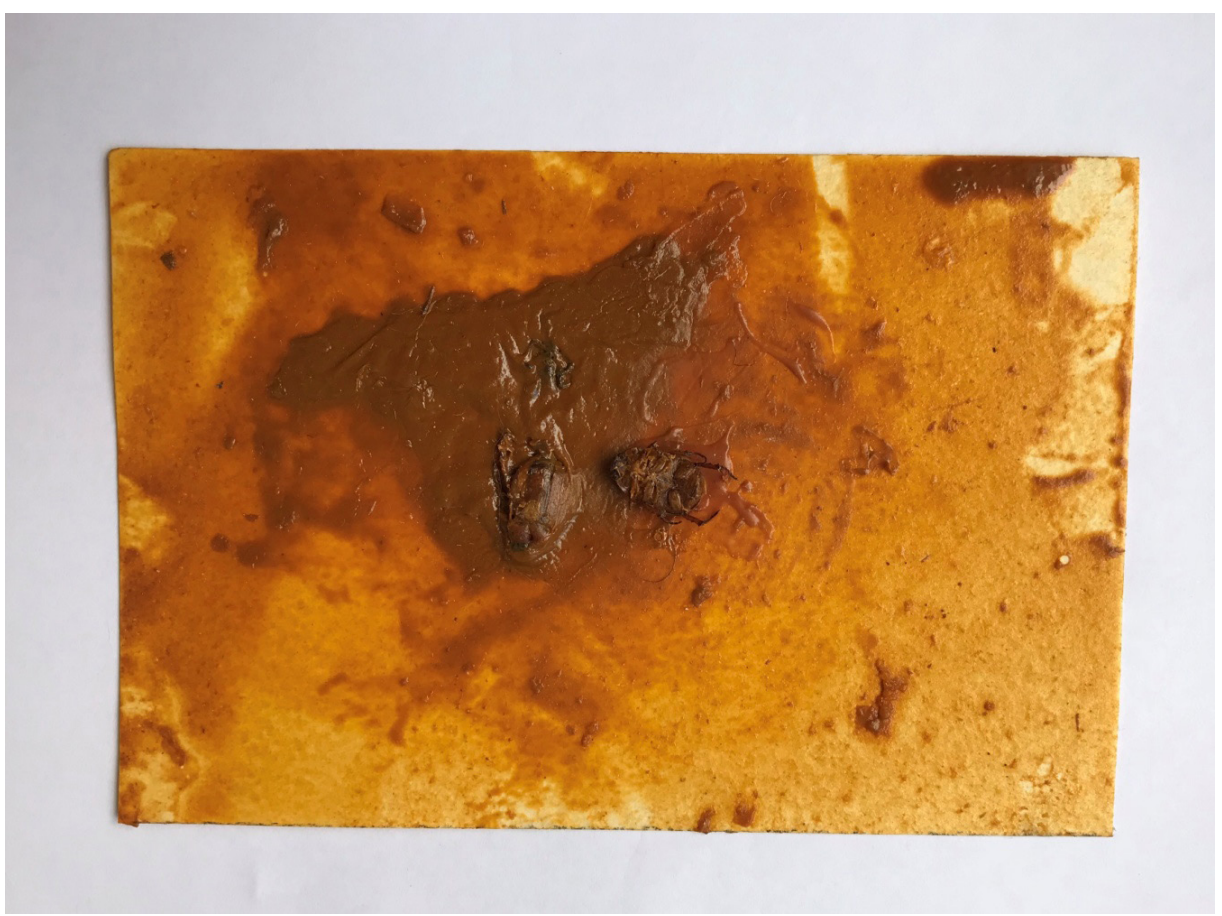

Figura 10 - Verão dos Besouros Amarelos [Correa, Helga. Verão dos Besouros Amarelos, 2018, colagem/verniz/matéria orgânica, $10 \times 14 \mathrm{~cm}$, coleção da artista]

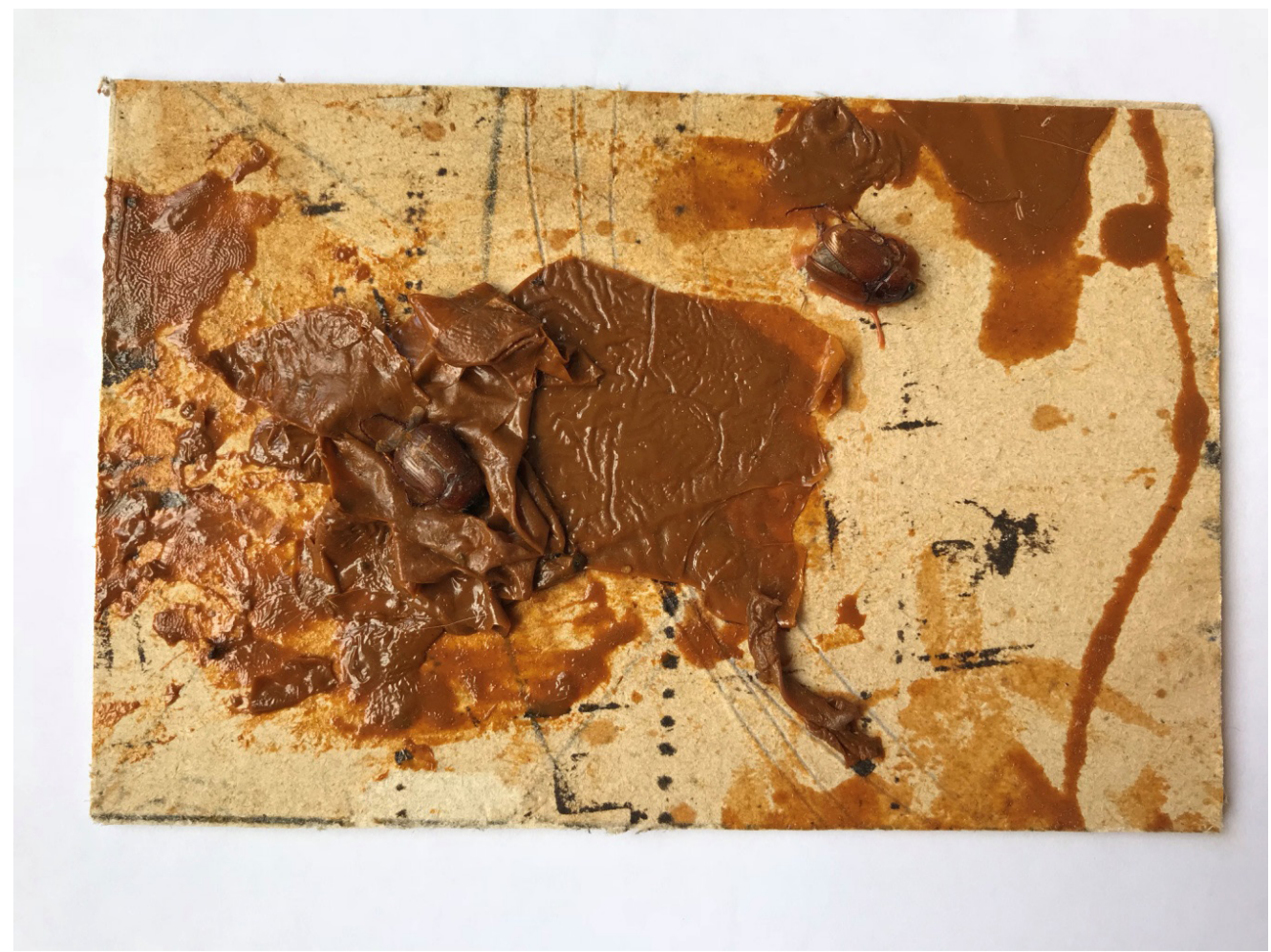

Comecei a observar essas mortes, as cores dos besouros em perfeita conexão com o tom amarelado do verniz e decidi incorporá-los às composições.

Esses animais que me rodearam nesse período trouxeram consigo a lembrança das tragédias ambientais, o desvela- 
mento de derramamentos, de contaminações, dos resíduos que produzimos. Fazendo uma analogia conosco, os besouros amarelos eram absolutamente insignificantes, suas mortes não alteravam em nada o curso da nossa vida.

Engendrando visibilidade a estes seres, encontrava um modo de enaltecê-los em suas mortes.

Mas o vivo e o inerte produzem asco, incomodo. E neste caso nos remetem aos derramamentos, aos desmatamentos, a destruição provocada pelos homens, problematizando os limites de nossa sensibilidade.

Durante a exploração monocromática dos trabalhos, pude lembrar-me de Mariana, do Kuwait, da monocromia dos derramamentos, ao mesmo tempo terríveis e belas. Normalmente, tratamos de não pensar e não nos posicionar ante esses desastres, tratamos a nós próprios e a nossa casa como se fossemos aqueles besouros, morrendo aos poucos enlameados pelos resíduos que nós mesmos estamos produzindo.

\section{Considerações finais}

Surpreendentemente, vivemos em um mundo que simultaneamente atingiu um alto nível tecnológico em diferentes esferas da vida humana, mas que padece com problemas ambientais graves, como o tratamento dos resíduos gerados pelo próprio homem.

Países com alto padrão de sustentabilidade e qualidade de vida, onde esses problemas parecem superados, como é o caso da Noruega, aproveitam da vulnerabilidade de um país em desenvolvimento como o Brasil, para tratar com descaso o meio ambiente, descartando rejeitos de minérios em nascentes de rios brasileiros. Esse novo escândalo ambiental, ocorrido em 2018, mostrou que a noção de ecologia, de bem estar social e interdependência, tem validade em suas estritas fronteiras. Os altos indícios de chumbo, alumínio, sódio e outras substâncias prejudiciais à saúde humana e animal, jogados por dutos clandestinos nas águas brasileiras, sinalizam a incoerência e a perversão de países que propiciam aos seus concidadãos confortáveis padrões de vida.

Conforme o relato de Carmen Junquera, caso semelhante ocorreu na Espanha quando, em 1998, a empresa Sueca Boliden -Apirsa verteu seis milhões de metros cúbicos de lama tóxica no rio Agrío. Considerado o maior desastre ambiental do país, o caso segue impune e em tramitações judiciais.

Lamentavelmente, são casos onde o modo de desvelamento da usura são os rejeitos produzidos pelo ser humano. Dejetos e rejeitos podem ser de diferentes naturezas, mas dispomos de conhecimento e tecnologia passíveis de transformação.

Infelizmente, é precisamente a ambição desmedida que nos precipitará a viver em um mundo extremamente quente, com pouca variedade de fauna e flora e muita escassez, porque a relação da natureza obedece a uma dinâmica de interdependência que transcende fronteiras geográficas.

O contato com investigadores e artistas de outras áreas, também conectados à causa ecológica, ratificam que os problemas ambientais não podem ser entendidos isoladamente, mas como problemas interligados, sistêmicos, e que a alternativa para romper com essa dinâmica destrutiva que vivemos é a progressiva mudança de concepções, de valores, de percepções e de práticas compartilhadas pelas comunidades.

Um exemplo extremamente significativo é o trabalho colaborativo The Cosmopolitical Forest, levado a cabo pelos artistas Ursula Biemann e Paulo Tavares na região da Amazônia equatoriana. Ao expor a dramática expansão de atividades extrativistas em grande escala, contrapostas às múltiplas dimensões da floresta tropical como entidade física, legal e cosmológica, ganharam em uma batalha legal a jurisprudência para a terra.

Exemplos desta magnitude têm repercutido em uma mudança sensível na minha vida profissional e pessoal, a urgência em discutir e atuar no campo local.

Conformeexpus brevemente, tento de diferentes maneiras sensibilizar, provocar a reflexão sobre questões relativas à preservação da natureza.

Mesmo sendo extremamente reais, tais preocupações por vezes são consideradas utópicas, mas entendo que sendo um estado de consciência é algo do qual não se pode mais retroceder, o que me impele a seguir trabalhando.

Pensar em diferentes aspectos da causa ecológica através da arte, não significa uma busca da verdade, mas, sim, um modo de dar visibilidade à forma como as realidades se constituem, a partir da verdade das pessoas, ou seja, a realidade é gerada ao fazê-la.

\section{Referências}

PÈREZ, H. La naturaleza em el arte pós-moderno. Madrid: Ediciones Akal, 2004

OLIVARES, R. La distancia adequada. Exit-Express, 31 out. 2017 Disponível em: <https://exit-express.com / author / rosa-olivares / page/5/>. Acesso em: 21/03/2018.

RAQUEJO, T; PARREÑO, J. Arte y ecología: Madrid: Ediciones Universidad Nacional de Educación a Distancia, 2015.

BIEMANN, U. The Cosmo-Political Forest: a theoretical and aesthetic discussion of the video forest law. GeoHumanities, v.1, n.1, p.157-170, 2015. 